Piccolo, L. del, Haes, H. de, Heaven, C., Jansen, J., Verheul, W., Bensing, J., Bergvink, S., Deveugele, M., Eide, H., Fletcher, I., Goss, C., Humphries, G., Young-Mi, K., Langewitz, W., Mazzi, A., Mjaaland, T., Moretti, F., Nübling, M., Rimondini, M., Salmon, P., Sibbern, T., Skre, I., Dulmen, S. van, Wissow, L., Young, B., Zandbelt, L., Zimmermann, C., Finset, A. Development of the Verona coding definitions of emotional sequences to code health providers' responses (VR-CoDES-P) to patient cues and concerns. Patient Education and Counseling: 2011, 82(2), 149-155

\begin{tabular}{|l|l|}
\hline Postprint Version & 1.0 \\
\hline Journal website & $\underline{\text { http://dx.doi.org/10.1016/j.pec.2010.02.024 }}$ \\
\hline Pubmed link & $\underline{\text { http://www.ncbi.nlm.nih.gov/pubmed/20346609 }}$ \\
\hline DOI & $10.1016 /$ j.pec.2010.02.024 \\
\hline
\end{tabular}

\title{
Development of the Verona coding definitions of emotional sequences to code health providers' responses (VR-CoDES-P) to patient cues and concerns
}

Lidia Del PICCOLO ${ }^{\mathrm{A}}$, HANNEKE DE HAES ${ }^{\mathrm{B}}$, CATHY HEAVEN ${ }^{\mathrm{C}}$, JESSE JANSEN ${ }^{\mathrm{D}}$, E, WILliAM VERHEUL ${ }^{\mathrm{D}}$ JOZIEN BENSING ${ }^{\mathrm{D}}$, SVEIN BERGVIK ${ }^{\mathrm{F}}$, MYRIAM DEVEUGELE ${ }^{\mathrm{G}}$, HILDE EIDEH, IAN FLETCHER', ClAUdiA GOSS $^{A}$, GERRY HUMPHRIS ${ }^{J}$, YOUNG-MI KIM ${ }^{\mathrm{K}}$, WOLF LANGEWITZ ${ }^{\mathrm{L}}$, MARIA ANGELA MAZZI ${ }^{\mathrm{A}}$, TROND MJAALAND $^{\mathrm{M}}$, FRANCESCA MORETTI ${ }^{\mathrm{A}}$, MATTHIAS NÜBLING ${ }^{\mathrm{N}}$, MiCHELA RIMONDINI ${ }^{\mathrm{A}}$ PETER SALMONI, TONJ $^{\mathrm{E}}$ SIBBERNH, INGUNN SKRE ${ }^{\mathrm{O}}$, SANDRA VAN DULMEN ${ }^{\mathrm{D}}$, LARRY WISSOW ${ }^{\mathrm{P}}$, BRIDGET YOUNG ${ }^{\mathrm{I}}$, LINDA ZANDBELT $^{\mathrm{B}}$, CHRISTA ZIMMERMANN ${ }^{\mathrm{A}}$ AND ARNSTEIN FINSET ${ }^{\mathrm{M}}$

${ }^{a}$ Department of Medicine and Public Health, Section of Psychiatry and Clinical Psychology, University of Verona, Policlinico G.B. Rossi General Hospital, Piazzale L.A. Scuro 10, 37134 Verona, Italy

${ }^{\mathrm{b}}$ Department of Medical Psychology, Academic Medical Centre, University of Amsterdam, Amsterdam, Netherlands

${ }^{c}$ Maguire Communication Skills Training Unit, The Christie NHS Foundation Trust, Manchester, UK

${ }^{d}$ Netherlands Institute for Health Services Research (NIVEL), Utrecht, Netherlands

e Sydney School of Public Health, Centre for Medical Psychology and Evidence-based Decision Making, University of Sydney, Australia

${ }^{f}$ Department of Clinical Psychiatry, University of Tromsø and University Hospital of Northern Norway, Tromsø, Norway

${ }^{9}$ Department of General Practice and Primary Health Care, University of Ghent, Ghent, Belgium

${ }^{\mathrm{h}}$ Department of Nursing, Oslo University College, Oslo, Norway

' Division of Clinical Psychology, Whelan Building, University of Liverpool, Liverpool, UK

${ }^{j}$ Health Psychology, Bute Medical School, University of St Andrews, St. Andrews, UK

${ }^{k}$ Johns Hopkins Program for International Education in Gynecology and Obstetrics (JHPIEGO), Baltimore, USA

' Psychosomatic Medicine/Internal Medicine, University Hospital Basel, Basel, Switzerland

${ }^{m}$ Institute of Basic Medical Science, Faculty of Medicine, University of Oslo, Oslo, Norway

${ }^{\mathrm{n}}$ GEB, Empirical Consulting, Freiburg, Germany

${ }^{\circ}$ Department of Psychology, Faculty of Health Sciences, University of Tromsø, Tromsø, Norway

${ }^{\mathrm{p}}$ School of Public Health, Johns Hopkins University, Baltimore, USA

\section{Abstract}

Objective: To present a method to classify health provider responses to patient cues and concerns according to the VR-CoDES-CC (Del Piccolo et al. (2009) [2] and Zimmermann et al. (submitted for publication) [3]). The system permits sequence analysis and a detailed description of how providers handle patient's expressions of emotion.

Methods:The Verona-CoDES-P system has been developed based on consensus views within the "Verona Network of Sequence Analysis". The different phases of the creation process are described in detail. A reliability study has been conducted on 20 interviews from a convenience sample of 104 psychiatric consultations.

Results 
Piccolo, L. del, Haes, H. de, Heaven, C., Jansen, J., Verheul, W., Bensing, J., Bergvink, S., Deveugele, M., Eide, H., Fletcher, I., Goss, C., Humphries, G., Young-Mi, K., Langewitz, W., Mazzi, A., Mjaaland, T., Moretti, F., Nübling, M., Rimondini, M., Salmon, P., Sibbern, T., Skre, I., Dulmen, S. van, Wissow, L., Young, B., Zandbelt, L., Zimmermann, C., Finset, A. Development of the Verona coding definitions of emotional sequences to code health providers' responses (VR-CoDES-P) to patient cues and concerns. Patient Education and Counseling: 2011, 82(2), 149-155

The VR-CoDES-P has two main classes of provider responses, corresponding to the degree of explicitness (yes/no) and space (yes/no) that is given by the health provider to each cue/concern expressed by the patient. The system can be further subdivided into 17 individual categories. Statistical analyses showed that the VR-CoDES-P is reliable (agreement $92.86 \%$, Cohen's kappa $0.90( \pm 0.04) p<0.0001)$.

Conclusion: Once validity and reliability are tested in different settings, the system should be applied to investigate the relationship between provider responses to patients' expression of emotions and outcome variables.

Practice implications: Research employing the VR-CoDES-P should be applied to develop research-based approaches to maximize appropriate responses to patients' indirect and overt expressions of emotional needs.

\section{INTRODUCTION}

\subsection{Cues and concerns and provider responses}

In a recent review on the literature on cues and concerns by patients in medical consultations, a high variability emerged in the definition of methodological approaches to these two types of patient expressions [1]. Definitions varied widely in detail and covered more or less different content areas, impeding a fruitful comparison of results and data. Hence an international group of experts in health communication research, "The Verona Network on Sequence Analysis" (authors of the present paper) decided to meet annually in Verona to find common ground and a shared language to define cues, concerns and the linked microbehaviours expressed by physicians. This collaborative convention gave rise to the elaboration of a new coding system, the VR-CoDES (Verona coding definitions of emotional sequences), where both patient cues and concerns are defined (VR-CoDES-CC) along with health provider responses to them (VRCoDES-P). In the VR-CoDES-CC cues are defined as "verbal or nonverbal hints, which suggest an underlying unpleasant emotion and that lack clarity" [2] and [3]. Concerns, are defined as "clear and unambiguous expressions of an unpleasant current or recent emotion that are explicitly verbalised with or without a stated issue of importance" [2] and [3].

In terms of health provider responses, cues and concerns constitute a source of information that may be distanced from, explored or acknowledged [4] and [5]. Yet, patients' cues and concerns are often underdetected and missed [1], [5] and [6]. They may be either not perceived or consciously ignored by health providers in order to hold control over their own agenda [7]. Still, many authors suggest that cues and concerns should be recognised and explored by health care providers, using information gathering skills as well as skills to help the patients expressing their concerns [2], [4], [5], [6] and [8].

Communication teachers assume that health providers should be open to cues and concerns and explore their content. However, little empirical evidence supporting the effectiveness of specific responses to cues is available. Zimmermann et al. cite in their recent review [1] only one study by Butow et al. looking at patient satisfaction and anxiety as related to cue responses with cancer patients [9]. Patient satisfaction and state anxiety turned out to be unaffected by physicians' reactions to informational and emotional cues. However, Uitterhoeve et al. found that cue response by oncology nurses was independently and positively related to patient satisfaction

One can imagine that in some situations, exploring concerns might be counterproductive. Some patients might be less appreciative of empathic behaviour and might prefer a more directive style [10]. Thus a facilitating response which is effective in one context can be ineffective in another. For example, follow up care may be different from emergency medicine. If so, the health provider would need to adopt a tailored approach rather than uniformly exploring such patient concerns. Indeed, Floyd et al. found that, depending on the way patients expected to present a symptom, i.e., with or without a cue and/or concern, they preferred a different response style on the part of the physician: some favoured a biomedical response whereas others preferred facilitation and even exploration [11]. The question of under what circumstances, with which patients, what reactions to patient cues and concerns are adequate and effective has to be settled empirically to support clinical teaching and practice. To substantiate these processes one has to identify 
Piccolo, L. del, Haes, H. de, Heaven, C., Jansen, J., Verheul, W., Bensing, J., Bergvink, S., Deveugele, M., Eide, H., Fletcher, I., Goss, C., Humphries, G., Young-Mi, K., Langewitz, W., Mazzi, A., Mjaaland, T., Moretti, F., Nübling, M., Rimondini, M., Salmon, P., Sibbern, T., Skre, I., Dulmen, S. van, Wissow, L., Young, B., Zandbelt, L., Zimmermann, C., Finset, A. Development of the Verona coding definitions of emotional sequences to code health providers' responses (VR-CoDES-P) to patient cues and concerns. Patient Education and Counseling: 2011, 82(2), 149-155

certain reactions of providers to cues and concerns under given conditions and to associate these to outcomes.

A prerequisite for this is to have a coding system for health provider responses to patient emotional cues and concerns. Such a system should provide a neutral perspective for coding provider responses. Criteria of appropriateness should not be built into the definition of the codes to avoid circularity in the associations between provider responses and outcome measures. Also, such a system should distinguish provider responses that are relevant according to theoretical and clinical knowledge. There are some coding systems that are partly based on these principles [12], [13], [14] and [15]. However, there is little consensus in definitions among these coding systems and the theoretical background is not always the same. The VRCoDES-P represents the result of a shared effort in finding a general consensus among different experts in health communication research. The present paper aims to show the conceptual and the procedural outcomes that the "Verona Network on Sequence Analysis" has reached on evaluating health provider's behaviour in response to emotional talking by the patient as described in the VR-CoDES-CC system for patient cues and concerns [2] and [3].

\section{METHODS}

The development process has involved a number of steps. First, a position paper was written within the group in 2006 to formulate the basic considerations underlying the development process [16]. It was decided not to code "appropriateness" in order to avoid value judgments inherent in the terms appropriate and inappropriate, and to focus instead on what seems to be the function of the utterance. Moreover it was also underlined that appropriateness should not be specified a priori, but should be hypothesized and tested empirically in relation to outcome measures and context (family background, individual characteristics, medical condition, shared knowledge, previous visits, etc.). After some anchoring points were identified, a small group of participants was delegated to reconsider the conceptual framework.

In 2007 [17] the cue/concern-related provider talk system was organized as a matrix based on three main factors or axes: (1) inhibiting vs. facilitating more talk about the cue/concern. (2) Implicit vs. explicit reference to the cue/concern. (3) Immediate vs. delayed response. Some pilot video tapes from a skills lab examination were coded by two members of the subgroup $(\mathrm{HdH}, \mathrm{JJ})$ to investigate whether working with the coding framework was feasible. Based on these early experiences the initial framework was revised. The next version of the framework was discussed within the Verona network in February 2008 and 2009 to establish its feasibility and conceptual clarity within a larger group (30 researchers, clinicians and teachers from nine countries). These discussions were based on the coding of three transcripts and one video from general practice and oncology consultations. Interviews were coded within small groups, whose members reached an agreement on the final coding. These small group sessions were followed by plenary sessions where disagreements were discussed to better define the coding system. The resulting framework is described in Section 3.

A first inter-rater reliability analysis on the use of the VR-CoDES-P was conducted on 20 interviews randomly selected from a convenience sample of 104 first outpatient consultations audio taped during the routine clinical practice in the south Verona Community Mental Health Service (CMHS) in the period 2002-2003. Consultations were rated by two expert raters (CZ and LDP). Percentage agreement and Cohen's kappa were adopted as reliability measures.

\section{RESULTS: DESCRIPTION OF THE CODING SYSTEM}

The coding system is specified in detail in the Coding Manual [18] and in a separate memorandum on units of analysis [19]. It can be accessed on the EACH web site (http://www.each.nl). The core feature of the system is that it intends to be descriptive and not normative in the sense that it does not distinguish between good and bad responses.

\subsection{Coding principles}

The coding of provider responses is dependent upon the coding of cues and concerns. Therefore the first step in the coding procedure is to identify cues and concerns according to the coding rules of the VRCoDES-CC manual [2]. In order to aid the coding procedure in subsequent steps it is important to identify the specific words (whenever the cue is verbal) used to express the cue or concern, both in terms of affect 
Piccolo, L. del, Haes, H. de, Heaven, C., Jansen, J., Verheul, W., Bensing, J., Bergvink, S., Deveugele, M., Eide, H., Fletcher, I., Goss, C., Humphries, G., Young-Mi, K., Langewitz, W., Mazzi, A., Mjaaland, T., Moretti, F., Nübling, M., Rimondini, M., Salmon, P., Sibbern, T., Skre, I., Dulmen, S. van, Wissow, L., Young, B., Zandbelt, L., Zimmermann, C., Finset, A. Development of the Verona coding definitions of emotional sequences to code health providers' responses (VR-CoDES-P) to patient cues and concerns. Patient Education and Counseling: 2011, 82(2), 149-155

and cue/concern-related content as well as its key elements. The provider expression - verbal or nonverbal - immediately following a cue or concern expressed by a patient should be coded as the response.

The provider responses are coded according to two major conceptual factors or axes: explicitness and space provision for further disclosure of the cue or concern. These factors are independent, that is, there is no fixed order in their coding. They are described and explained below, followed by the individual codes that give finer detail on the specific function of the response.

\subsubsection{Explicit vs. non-explicit responses}

The principal distinction between a cue and a concern is whether or not the emotional component of the concern is explicit. The same distinction is considered important in the provider response.

To be coded as explicit, a response should include either a specific or an explicit reference to the words in the preceding cue or concern, or be very clear in that it unambiguously refers to the stated cue or concern.

A cue or concern will often include both a topic and an emotion (e.g. "This stomach ache (topic) worries me a lot (emotion)"). To be coded as explicit the response must refer to either the content, or the emotion, or both, with no ambiguity whatsoever. When a slightly different wording is used (e.g. Patient: "I feel really down". Provider: "So you feel depressed") the response may be considered explicit only if it represents an unequivocal attempt to understand the cue or concern, otherwise the non-explicit category should be used.

A non-explicit response is any response which does not specifically or explicitly mention either the content or the emotion of the cue or concern or is ambiguous. Note that the opposite of explicit is labelled non-explicit, not implicit. To characterize a response as implicit would indicate that there is an element of recognition of the concern, but that it is not made explicit. The word non-explicit does not presume any recognition of the concern and is therefore broader and more precise. Moreover, the coding system refers to visible behaviour rather than any assumptions about intentions. Nonverbal responses not accompanied by a verbal response will always be coded as non-explicit, for example nodding or a hand gesture.

\subsubsection{Providing space vs. reducing space}

The second crucial factor is whether the response gives space or reduces space for further disclosure. Providing space refers to any response that actively or passively invites or allows the patient to say more about their cue/concern or worry. The provider is rated as reducing space for further disclosure when he or she, for example, ignores the cue or concern, introduces a 'switch', postpones a discussion of the cue/concern, actively blocks or offers any other behaviour which reduces the opportunity for the patient to say more about the cue or concern. This includes information or advice giving.

\subsubsection{Individual codes}

In order to provide more detailed description for training and research purposes, the four main classes obtained after the coding of the two main factors may be further subdivided. The final system has seventeen specified main individual categories (see Fig. 1). To allow comparison between categories, examples will be responses to the same concern: a patient in an in-patient surgical unit tells the doctor that he is "...so worried (emotion) about the operation (topic)" that is scheduled later in the week. More elaborate explanations of the different codes can be found in the online manual (http://www.each.nl).

\section{[FIGURE 1]}

\subsubsection{Non-explicit responses reducing space for further disclosure}

The coding system includes three categories of non-explicit responses in which the provider does not invite further elaboration of the cue or the concern. The first category is ignoring the cue or concern. No reference is made whatsoever to the cue or concern, neither to the content nor to the emotion. Moreover, an inattentive and uninviting silence of over $3 \mathrm{~s}$ (e.g. the health provider looks at the computer screen) should also be coded as ignoring. The second category is an active shutting down of the concern. The response remains non-explicit, as if the doctor in our example responds to the patient's worry by saying something like “Oh, don't be silly!”. Thirdly, with non-explicit information or advice the provider may give advice or 
Piccolo, L. del, Haes, H. de, Heaven, C., Jansen, J., Verheul, W., Bensing, J., Bergvink, S., Deveugele, M., Eide, H., Fletcher, I., Goss, C., Humphries, G., Young-Mi, K., Langewitz, W., Mazzi, A., Mjaaland, T., Moretti, F., Nübling, M., Rimondini, M., Salmon, P., Sibbern, T., Skre, I., Dulmen, S. van, Wissow, L., Young, B., Zandbelt, L., Zimmermann, C., Finset, A. Development of the Verona coding definitions of emotional sequences to code health providers' responses (VR-CoDES-P) to patient cues and concerns. Patient Education and Counseling: 2011, 82(2), 149-155

offer reassurance in a way that does not open space for further disclosure, and without mentioning the concern (e.g. "Everything will be fine").

\subsubsection{Non-explicit responses providing space for further disclosure}

A non-explicit response may also provide space for further disclosure and facilitate communication about a concern. A short nonverbal, attentive silence may effectively invite the patient to talk about the concern, as well as any response which provides space for the patient to encourage further disclosure, through using a minimal prompt, or word, but not a full statement, which is defined as back-channel (e.g. "OK, right...”). An implicit comment beyond the minimal back-channelling could be an acknowledgement (e.g. "Are you really?"), which provides space for the patient to elaborate on a cue or concern. Even more clearly inviting, but still implicit in relation to the concern, is an active invitation, which explicitly seeks further disclosure or new information without making explicit reference to the content or the emotion mentioned (e.g. "Would you like to tell me more?"). Finally, if the health provider makes no reference to the concern but expresses his own feeling or understanding (e.g. "I understand") the response is considered as an implicit expression of empathy.

\subsubsection{Explicit responses reducing space for further disclosure}

Within the class of categories that explicitly reduce space, no distinction can be made as to whether the explicit reference is to the content or the emotion aspect of the concern. The first term, switching, is applied when the health provider uses a response which changes the frame of reference of the cue/concern (e.g. refers the patient to a third party/agency, e.g. "I think that you should talk to a nurse about it"; changes the time frame/period of the specific cue or concern, e.g. “Did you have similar symptoms in the past?”; or asks how a third party feels about the cue or concern). Secondly, postponing reduces space for talking about the concern there and then, even if it opens up for later (e.g. "I would like to talk with you about this in a minute"). Thirdly, information/advice refers to an explicit response to the cue or concern, which gives information or advice or offers reassurance. It acknowledges the cue or concern, but does not invite further disclosure (e.g. "You do not need to worry; it is a routine operation"). Fourth, in active blocking: the provider mentions the concern and explicitly refuses to talk about it (e.g. "Worrying does not do you any good").

\subsubsection{Explicit responses providing space for further disclosure}

When a provider explicitly mentions the cue/concern and provides further space to talk about it, it could make a difference whether the content or the emotion is mentioned. The same verbal behaviours may apply to content, affect or both. Hence when the health provider echoes, reflects back, paraphrases, summarizes or checks a patient's expression, the adopted code will be an acknowledgement. If the health provider refers to the factual content or topic of the cue or concern without referring to the emotional element (e.g. "the operation?") the code will be acknowledgement of content. If the health provider refers to the emotional aspect of the cue or concern (e.g. "worried?") it will be an acknowledgement of affect.

The provider may also explore the content (e.g. “what operation are you going to have?”), or explore the affect (or both content and affect, e.g. “why are you so worried for the operation?”).

Finally, with an empathic response the health provider empathises with the patient's predicament and, thus, legitimises or shares the patient's emotion. The emotion involved in the patient's cue or concern must be mentioned in an empathic response. These are statements of understanding or educated guesses, all coming after exploration of the affective part of the patient's expression (e.g. "I understand this must be really hard for you, especially as you are so scared about this operation").

\subsection{Procedural coding rules}

\subsubsection{Units of analysis}

The unit of analysis is any response by the health provider to each cue/concern expressed by the patient. It may correspond to the turn of speech of the health provider or to part of it-if the provider expresses more than one response to the cue or concern within the turn. If the patient expresses more than one cue or concern in the same turn, the response is rated in relation to each of the cues or concerns. For instance, if a 
Piccolo, L. del, Haes, H. de, Heaven, C., Jansen, J., Verheul, W., Bensing, J., Bergvink, S., Deveugele, M., Eide, H., Fletcher, I., Goss, C., Humphries, G., Young-Mi, K., Langewitz, W., Mazzi, A., Mjaaland, T., Moretti, F., Nübling, M., Rimondini, M., Salmon, P., Sibbern, T., Skre, I., Dulmen, S. van, Wissow, L., Young, B., Zandbelt, L., Zimmermann, C., Finset, A. Development of the Verona coding definitions of emotional sequences to code health providers' responses (VR-CoDES-P) to patient cues and concerns. Patient Education and Counseling: 2011, 82(2), 149-155

patient turn contains two cues (e.g. “... the pain is driving me mad, and I'm upset about my wife.”), the provider can respond to one of them (e.g. "How bad is your pain"), or both (e.g. "You mentioned your pain and also being upset about your wife") or none. The subsequent provider coding has to contain at least one code for each cue.

\subsubsection{Immediate and delayed responses}

A distinction is made between immediate and delayed responses. The immediate response refers to the provider speech unit(s) in the turn immediately following any cue or concern. All immediate responses must be coded, whatever their nature. However, the provider may also refer to a cue or concern in earlier speech units. These delayed responses should be coded only when the response of the provider is explicitly referred to a cue/concern from an earlier section.

\subsubsection{Nonverbal provider behaviour}

Nonverbal behaviour should be taken into account when coding because it impacts on the meaning and delivery of the words. For example, the rater should consider the providers' tone of voice, facial expression, or eye contact. Congruence or lack of congruence between verbal and nonverbal messages may help coders to decide between categories, and can facilitate decisions about behaviours which provide space or do not provide space. Videotapes contain more nonverbal information than audiotapes for which only tone of voice can be considered.

\subsubsection{Reliability}

All 104 consultations (39 with male patients) were transcribed and coded by expert raters. A subgroup of 20 consultations (8 with male patients) was randomly selected to investigate the reliability of the coding. Table 1 shows the ICD-10 diagnostic group of the general sample of patients and the subgroup selected to analyse inter-rater reliability.

\section{[TABLE 1]}

Health providers were 9 psychiatrists and 7 residents in psychiatry; 9 male, the mean age was 39 years (29-57) and clinical experience ranged between 3 and 32 years. Each psychiatrist contributed with a different range (1-15) of interviews. The utterances coded as cue/concern which were followed by an health provider response were 224 (10.4\% of the total number of turns). Table 2 shows the distribution of the VR-CoDES-P coding on the two main axes given by the two raters. Analyses showed that the VRCoDES-P is reliable (percentage agreement 92.9\%, Cohen's kappa $0.90( \pm 0.04) p<0.0001)$.

\section{[TABLE 2] [TABLE 3]}

\section{DISCUSSION AND CONCLUSION}

\subsection{Discussion}

We have introduced a new coding system, the VR-CoDES-P, devised to investigate health care providers' responses to cues and concerns, as defined by the VR-CoDES-CC. Four criteria were formulated. The system: (1) is limited to provider responses to cues and concerns. It is not designed to code all provider utterances, (2) builds on a precise definition of cues and concerns, (3) provides a neutral perspective for coding provider responses, (4) can provide data suitable for sequence analysis.

The selection of provider responses and their description is neither unique nor always novel. An important inspiration derived from the work by Heaven et al. [12] which finds support by Roter and Larson [20].

The VR-CoDES-P has several levels of analysis. It is based on two main factors or axes: whether the emotional experience is explicitly verbalised or not and the provider promotes further disclosure or not.

Demonstrating the importance of the first factor, a number of studies have applied brain imaging methods to investigate the effect of labelling emotionally evocative images For instance, Hariri et al. exposed their subjects to threatening and fearful non-face stimuli derived from the international affective picture system [21]. They either were given the stimuli without specific instructions or were told to verbalise the emotion 
Piccolo, L. del, Haes, H. de, Heaven, C., Jansen, J., Verheul, W., Bensing, J., Bergvink, S., Deveugele, M., Eide, H., Fletcher, I., Goss, C., Humphries, G., Young-Mi, K., Langewitz, W., Mazzi, A., Mjaaland, T., Moretti, F., Nübling, M., Rimondini, M., Salmon, P., Sibbern, T., Skre, I., Dulmen, S. van, Wissow, L., Young, B., Zandbelt, L., Zimmermann, C., Finset, A. Development of the Verona coding definitions of emotional sequences to code health providers' responses (VR-CoDES-P) to patient cues and concerns. Patient Education and Counseling: 2011, 82(2), 149-155

that was elicited from seeing the pictures. Brain imaging data revealed that just seeing the stimuli was associated with a bilateral amygdala response (amygdala activation is associated with emotional responses, mainly during fear conditioning [22]), whereas cognitive evaluation with a verbal labelling of the emotion, was associated with the reduction of this amygdala activation and with an increase in response of the right prefrontal cortex and the anterior cingulate cortex, which overruled the more primitive affective responses [23]. These findings indicate that by letting the patient express cues and concerns, the health professional helps the patient to regulate emotional processing in the brain, by stimulating the centres that 'down regulate' the negative emotions, corresponding to stress reduction [24].

The second axis, providing space for further disclosure is also important, as it helps to find common ground between both health provider and patient feelings, facilitating an affective coordination [25]. In analyses of interpersonal interaction this opening up for the other person is a fundamental dimension, both in the philosophy of human interaction (such as Buber's distinctions between "ich" (I), "du" (you) and "es" (it) [26]) and in a modern neuroscience-based understanding of phenomena such as rapport and empathy [23] and [24].

The VR-CoDES allows also researchers to adopt sequence analysis techniques. Sequence analysis allows an understanding of the temporal relationship between events focusing on interactions in terms of what communication behaviour precedes and what follows a target behaviour [1]. If we want evidence on the impact of provider responses to cues and concerns, interaction analysis systems need to describe the consultation process realistically and accurately, reflecting the dynamics of true interaction. To get beyond mere counting of utterances, the timing of events will have to be recorded [27] and [28]. Even if the introduction of sequential analysis presents challenging methodological and conceptual problems [29], [30] and [31], it permits us to study the natural course of events and thus provides a more valid picture of the actual communication processes.

\subsubsection{Reliability}

Reliability indices showed that the agreement between raters was substantial. The category "non-explicit reference to cue/concern" was rated slightly more often than explicitness by both raters (R1: 54.46\%; R2: $51.34 \%$ ). The same level of agreement was found for the provision of space axis (R1: 71.87\%; R2: 73.21\%). Nearly all individual categories were adopted by the raters, showing that the distinction between these categories is feasible and useful. A broader discussion on the frequency of all VR-CoDES categories and reliability outcomes will be presented in a forthcoming paper, specifically devoted to the application of the VR-CoDES in a psychiatric context.

\subsubsection{Limitations}

The VR-CoDES-P has some limitations. First, it covers only responses to negative emotions or worries, as defined in the VR-CoDES-CC. The choice was because negative emotions are more probably related to a concern. This does not exclude that, the provider might present emotionally salient remarks that are a response to a patient's positive emotion or a hint of a positive emotion. Secondly, in the system only responses, and not the preceding remarks to cues and concerns, are coded. In this case no parsimonious solution was found to solve the problem of responses that at the same time were elicitors. Thirdly, the system could have been even more specific if it provided details about specific skills such as whether an open or closed question was used in switching topic, or if the cue was acknowledged using a summary or a reflection. For this reason the VR-CoDES-P may be used along with another system, more specifically designed for communication skills. Fourth, nonverbal behaviour is not specified in detail in the coding system, albeit it is used as a way of getting to the Verona codes (e.g. the distinction between ignoring and silence based on nonverbal behaviour of the health provider). Finally, the VR-CoDES-P system is rather complicated and time consuming when using all 17 categories. To tap these it may be necessary to have a large dataset for analysis. However, there is preliminary evidence for the utility of a categorization based on the two main factors, which seem to be a realistic approach for most research questions.

\subsubsection{Further investigation}


Piccolo, L. del, Haes, H. de, Heaven, C., Jansen, J., Verheul, W., Bensing, J., Bergvink, S., Deveugele, M., Eide, H., Fletcher, I., Goss, C., Humphries, G., Young-Mi, K., Langewitz, W., Mazzi, A., Mjaaland, T., Moretti, F., Nübling, M., Rimondini, M., Salmon, P., Sibbern, T., Skre, I., Dulmen, S. van, Wissow, L., Young, B., Zandbelt, L., Zimmermann, C., Finset, A. Development of the Verona coding definitions of emotional sequences to code health providers' responses (VR-CoDES-P) to patient cues and concerns. Patient Education and Counseling: 2011, 82(2), 149-155

Several investigations are needed to further substantiate the use of the VR-CoDES-P system. Researchers may have different study aims. Some may wish to take a broad perspective in examining the effectiveness of communication. Whether or not responses are explicit is interesting in and of itself. For instance, is nonexplicit acknowledgement enough to make the patient feel acknowledged and that rapport is being built? This might depend on the medical and social context and on the patient's own preferences and it remains an empirical question. The same applies to whether or not providing space is effective. As suggested in the introduction, there are good reasons to believe that it is not always appropriate to explore the patient's cues at length. Patients may avoid (part of) the illness experience because the reality is too threatening [32]. It is, in fact, surprising that so little evidence is available to substantiate the relative impact of being explicit and providing space to patients' concerns. Our coding system will hopefully stimulate the provision of empirical evidence and eventually increase our understanding of basic mechanisms in patient and health care provider communication.

Other researchers may be interested in more specific communicative responses and may want to study the reactions of health care providers in detail. For example, Watzlawick and Jackson [33] have suggested that 'ignoring' is the most dismissive communicative message. In the VR-CoDES-P ignoring is coded when a cue or concern is ignored and no reference whatsoever is made to either the content or the emotion, and can be distinguished from the more active 'shutting down'. Which of these responses has a more negative impact remains to be established empirically. Learning about such subtle distinctions can be of particular interest to communication skills training.

Future studies should also clarify whether the VR-CoDES-P data should be supplemented by a qualitative approach to emotional communication. Finally, it is unclear how well the system will work in cultural contexts different from the one in which it has been developed. Even though this initial phase involved researchers from many different countries and different cultural settings, most of the early work has evolved from a western perspective.

\subsection{Conclusions}

The Verona-CoDES-P system to code provider responses to patient cues and concerns has been developed based on consensus within the Verona Network of Sequence Analysis. This is the first attempt to bring together the experience and competence of researchers from different backgrounds to define a common classification system, which might facilitate comparative research on the basis of a shared language. The system, when applied in a psychiatric context has been shown to be reliable. If found sufficiently valid and reliable also in other contexts, the system can play an important role in the development of evidence-based communication.

\subsection{Practice implications}

Research applying the VR-CoDES-P should be applied to develop research-based approaches to communication skills training.

\subsubsection{Information for users}

For the correct application of the VR-CoDES, the network has developed a training package of coding exercises, obtainable on request. The manuals of the VR-CoDES (VR-CoDES-CC, VR-CoDES-P and VRCoDES-Units of Analysis) are available to interested researchers free of charge on http://www.each.eu. New users are strongly recommended to complete the exercises of the training package and, subsequently, to conduct a reliability study with their own transcript/video data to ensure minimal quality standards.

\section{ACKNOWLEDGEMENTS}

The VR-CoDES-P is the result of the combined efforts of a group of European and American researchers from the "Verona Network on Sequence Analysis".

Contributors: Jozien Bensing, Utrecht NL; Svein Bergvik, Tromso NO; Lidia Del Piccolo, Verona IT; Claudia Goss, Verona IT; Hanneke de Haes, Amsterdam NL; Stephanie Demaesschalck, Gent BE; Hilde Eide, Oslo NO; Tom Eide, Oslo NO; Arnstein Finset, Oslo NO; Ian Fletcher, Liverpool UK; Cathy Heaven, Manchester UK; Gerry Humphris, St. Andrews UK; Wolf Langewitz, Basel CH; Jesse Jansen, Utrecht NL; Young-Mi Kim, Baltimore USA; Mariangela Mazzi, Verona IT; Ludwien Meeuwesen, Utrecht NL; Trond 
Piccolo, L. del, Haes, H. de, Heaven, C., Jansen, J., Verheul, W., Bensing, J., Bergvink, S., Deveugele, M., Eide, H., Fletcher, I., Goss, C., Humphries, G., Young-Mi, K., Langewitz, W., Mazzi, A., Mjaaland, T., Moretti, F., Nübling, M., Rimondini, M., Salmon, P., Sibbern, T., Skre, I., Dulmen, S. van, Wissow, L., Young, B., Zandbelt, L., Zimmermann, C., Finset, A. Development of the Verona coding definitions of emotional sequences to code health providers' responses (VR-CoDES-P) to patient cues and concerns. Patient Education and Counseling: 2011, 82(2), 149-155

Mjaaland, Oslo NO; Suzan Monca, St.Andrews UK; Francesca Moretti, Verona IT; Matthias Nübling, Freiburg DE; Monica Paccaloni, Verona IT; Michela Rimondini, Verona IT; Johanna Ruusuvuori, Tampere FI; Peter Salmon, Liverpool UK; Tonje Sibbern, Oslo NO; Ingunn Skre, Tromsø NO; Ellen Smets, Amsterdam NL; Sandra van Dulmen, Utrecht NL; William Verheul, Utrecht NL; Rolf Winn, Tromsø NO; Larry Wissow, Baltimore USA; BridgetYoung, Liverpool UK; Linda Zandbelt, Amsterdam NL; Christa Zimmermann, Verona IT.

\section{REFERENCES}

[1] Zimmermann C, Del Piccolo L, Finset A. Cues and concerns by patients in medical consultations: a literature review. Pychol Bull 2007;133:438-63.

[2] Del Piccolo L, Finset A, Zimmermann C. Verona coding definitions of emotional sequences (VRCoDES). Cues and concerns manual; 2009, http://www.each.eu.

[3] Zimmermann C, Del Piccolo L, Bensing J, Bergvik S, De Haes H, Eide H, et al. Coding patient cues and concerns in medical consultations: The Verona coding definitions of emotional sequences (VR-CoDES). Cues and Concerns Manual, submitted for publication.

[4] Uitterhoeve R, de Leeuw J, Bensing J, Heaven C, Borm G, deMulder P, van Achterberg T. Cueresponding behaviours of oncology nurses in video-simulated interviews. J Adv Nurs 2008;61:71-80.

[5] Heaven C, Clegg J, Maguire P. Transfer of communication skills training from workshop to workplace: the impact of clinical supervision. Patient Educ Couns 2006;60:313-25.

[6] Hulsman RL, Harmsen AB, Fabriek M. Reflective teaching of medical communication skills with DiViDU: assessing the level of student reflection on recorded consultations with simulated patients. Patient Educ Couns 2009; 74:142-9.

[7] Cocksedge S, May C. The listening loop: a model of choice about cues within primary care consultations. Med Ed 2005;39:999-1005.

[8] Maguire P, Faulkner A, Booth K, Elliott C, Hillier V. Helping cancer patients disclose their concerns. Eur J Cancer 1996;32:78-81.

[9] Butow PN, Brown RF, Gogar S, Tattersall MHN, Dunn SM. Oncologists' reactions to cancer patients' verbal cues. Psycho-Oncology 2002;11:47-58.

[10] de Haes JCJM. Dilemmas in patient centeredness and shared decision making: a case for vulnerability. Patient Educ Couns 2006;62:291-8.

[11] Floyd MR, Lang F, McCord RS, Keener M. Patients with worry: presentation of concerns and expectations for response. Patient Educ Couns 2005;57:211-6.

[12] Heaven C, Green C, Schofield N, Fletcher I, Maguire P. Medical Interview Aural Rating Scale. CRC Psychological Medicine Group, Unpublished Manuscript, University of Manchester.

[13] Dent E, Brown R, Dowsett S, Tattersall M, Butow P. The Cancode interaction analysis system in the oncological setting: reliability and validity of video and audio tape coding. Patient Educ Couns 2005;56:35-44.

[14] Bylund CL, Makoul G. Empathic communication and gender in the physician- patient encounter. Patient Educ Couns 2002;48:207-16.

[15] Suchman AL, Markakis K, Beckman HB, Frankel R. A model of empathic communication in the medical interview. J Am Med Assoc 1997;277:678-82.

[16] Del Piccolo L, Goss C, Bergvik S. The fourth meeting of the Verna Network of Sequence Analysis. Consensus finding on the appropriateness of provider responses to patient cues and concerns. Patient Educ Couns 2006;61:473-5.

[17] Bergvik S, Del Piccolo L. The fifth meeting of the Verna Network of Sequence Analysis. In: Coding of health provider talk to patient cues and concerns; 2007, http://www.each.eu.

[18] Del Piccolo L, de Haes H, Heaven C, Jansen J, Verheul W, Finset A. Verona coding definitions of emotional sequences (VR-CoDES). Provider responses manual; 2009, http://www.each.eu.

[19] Del Piccolo L, Mazzi MA. Verona coding definitions of emotional sequences (VR-CoDES). In: Rational for dividing a consultation into units of analysis; 2009, http://www.each.eu.

[20] Roter D, Larson S. The Roter interaction analysis system (RIAS): utility and flexibility for analysis of medical interactions. Patient Educ Couns 2002;46: 243-25116.

[21] Hariri AR, Bookheimer SY, Mazziotta JZ. Modulating emotional responses: effects of a neocortical network on the limbic system. Neuroreport 2000; 11:43-8.

[22] Amunts K, Kedo O, Kindler M, Pieperhoff P, Mohlberg H, Shah N, Habel U, Schneider F, Zilles K. Cytoarchitectonic mapping of the human amygdala, hippocampal region and entorhinal cortex: intersubject variability and probability maps. Anat Embryol 2005;210:343-52. 
Piccolo, L. del, Haes, H. de, Heaven, C., Jansen, J., Verheul, W., Bensing, J., Bergvink, S., Deveugele, M., Eide, H., Fletcher, I., Goss, C., Humphries, G., Young-Mi, K., Langewitz, W., Mazzi, A., Mjaaland, T., Moretti, F., Nübling, M., Rimondini, M., Salmon, P., Sibbern, T., Skre, I., Dulmen, S. van, Wissow, L., Young, B., Zandbelt, L., Zimmermann, C., Finset, A. Development of the Verona coding definitions of emotional sequences to code health providers' responses (VR-CoDES-P) to patient cues and concerns. Patient Education and Counseling: 2011, 82(2), 149-155

[23] Liebermann MD. Social cognitive neuroscience: a review of core processes. Ann Rev Psychol 2007;58:259-89.

[24] Finset A, Mjaaland T. The medical consultation viewed as a value chain: a neurobehavioral approach

to emotion regulation in doctor-patient interaction. Patient Educ Couns 2009;74:323-30.

[25] Beebe B, Jaffe J, Lachmann F, Feldstein S, Crown C, Jasnow M. Systems models in development and psychoanalysis: the case of vocal rhythm coordination and attachment. Infant Ment Health J 2000;21:99122.

[26] Buber M. I and thou (English translation). New York: Free Press; 1971.

[27] Wasserman RC, Inui TS. Systematic analysis of clinician-patient interactions: a critique of recent approaches with suggestions for future research. Med Care 1983;21:279-93.

[28] Heaven C, Maguire P, Green C. A patient-centred approach to defining and assessing interviewing competency. Epidemiol Psichiatr Soc 2003;12:86-91.

[29] Mazzi MA, Del Piccolo L, Zimmermann C. Event based categorical sequential analyses of the medical interview: a review. Epidemiol Psichiatr Soc 2003;12:81-5.

[30] Del Piccolo L, Mazzi MA, Dunn G, Sandri M, Zimmermann C. Sequence analysis in multilevel models.

A study on different sources of patient cues in medical consultations. Soc Sci Med 2007;65:2357-70.

[31] Connor M, Fletcher I, Salmon P. The analysis of verbal interaction sequences in dyadic clinical

communication: a review of methods. Patient Educ Couns 2009;75:169-77.

[32] Vos MS, de Haes JCJM. Denial in cancer patients, an explorative review. Psycho-Oncology 2007;16:12-25.

[33] Watzlawick B, Jackson D. Pragmatics of human communication. New York: Norton; 1967.

\section{FIGURES}

Fig. 1. The Verona coding definitions of emotional sequences for the health Provider (VR-CoDES-P) flow chart.

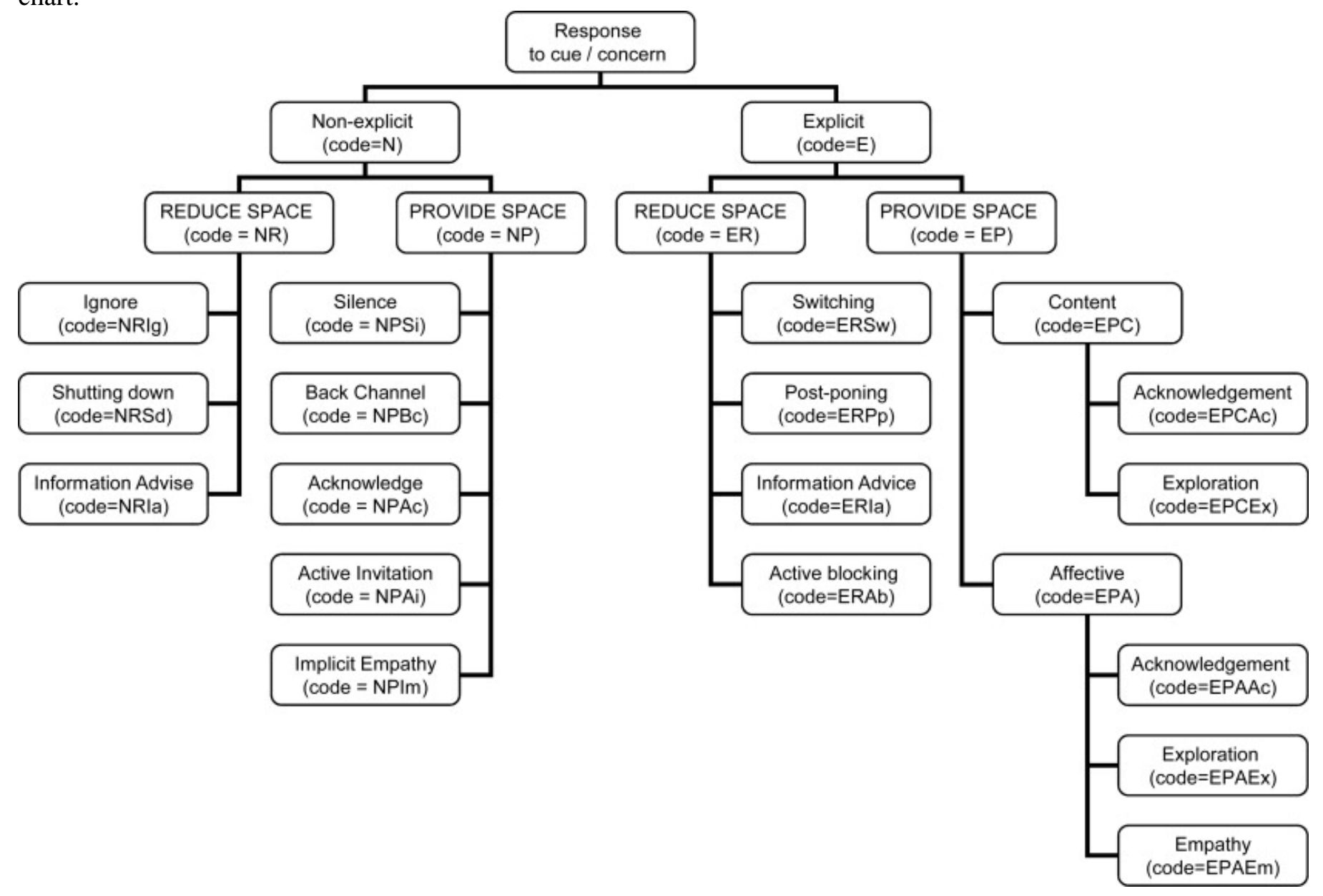


Piccolo, L. del, Haes, H. de, Heaven, C., Jansen, J., Verheul, W., Bensing, J., Bergvink, S., Deveugele, M., Eide, H., Fletcher, I., Goss, C., Humphries, G., Young-Mi, K., Langewitz, W., Mazzi, A., Mjaaland, T., Moretti, F., Nübling, M., Rimondini, M., Salmon, P., Sibbern, T., Skre, I., Dulmen, S. van, Wissow, L., Young, B., Zandbelt, L., Zimmermann, C., Finset, A. Development of the Verona coding definitions of emotional sequences to code health providers' responses (VR-CoDES-P) to patient cues and concerns. Patient Education and Counseling: 2011, 82(2), 149-155

\section{TABLES}

Table 1. ICD-10 diagnostic group of the general sample of patients and the subgroup selected to analyse inter-rater reliability.

\begin{tabular}{|c|c|c|c|c|}
\hline \multirow{2}{*}{ ICD-10 diagnostic group } & \multicolumn{2}{|c|}{ General sample } & \multicolumn{2}{|c|}{ Inter-rater sample } \\
\hline & $n$ & $\%$ & $n$ & $\%$ \\
\hline Depression without psychosis & 40 & 38.5 & 7 & 35.0 \\
\hline Anxiety, somatoform and stress related disorders & 37 & 35.6 & 7 & 35.0 \\
\hline Personality disorders & 3 & 2.9 & 1 & 5.0 \\
\hline Schizophrenia & 2 & 1.9 & 0 & 0.0 \\
\hline Organic syndromes & 1 & 1.0 & 0 & 0.0 \\
\hline Other diagnosis & 10 & 9.6 & 3 & 15.0 \\
\hline No psychiatric diagnosis & 11 & 10.6 & 2 & 10.0 \\
\hline Total & 104 & 100 & 20 & 100 \\
\hline
\end{tabular}

Table 2. Reliability of the coding of the two factors of the VR-CoDES-P provides space (P)/reduce space (R) and non-explicit (N)/explicit (E) combined together.

\begin{tabular}{|l|l|l|l|l|l|}
\hline Rater 2 & \multicolumn{3}{|l|}{ Rater 1 } & Total \\
\cline { 2 - 6 } & NR & NP & ER & EP & \\
\hline NR & - & - & - & - & \\
\hline NP & 39 & 0 & 0 & 1 & 40 \\
\hline ER & 3 & 71 & 0 & 1 & 75 \\
\hline EP & 2 & 0 & 16 & 2 & 20 \\
\hline & 3 & 4 & 0 & 82 & 89 \\
\hline Total & 47 & 75 & 16 & 86 & 224 \\
\hline
\end{tabular}


Piccolo, L. del, Haes, H. de, Heaven, C., Jansen, J., Verheul, W., Bensing, J., Bergvink, S., Deveugele, M., Eide, H., Fletcher, I., Goss, C., Humphries, G., Young-Mi, K., Langewitz, W., Mazzi, A., Mjaaland, T., Moretti, F., Nübling, M., Rimondini, M., Salmon, P., Sibbern, T., Skre, I., Dulmen, S. van, Wissow, L., Young, B., Zandbelt, L., Zimmermann, C., Finset, A. Development of the Verona coding definitions of emotional sequences to code health providers' responses (VR-CoDES-P) to patient cues and concerns. Patient Education and Counseling: 2011, 82(2), 149-155

Table 3. Two raters agreement on each of the VR-CoDES-P codes.

\begin{tabular}{|c|c|c|}
\hline VR-CoDES-HP code & Frequency & $\%$ \\
\hline EPAAс & 9 & 4.3 \\
\hline EPAEm & 3 & 1.4 \\
\hline EPAEx & 35 & 16.8 \\
\hline EPCAc & 5 & 2.4 \\
\hline EPCEx & 30 & 14.4 \\
\hline ERIa & 14 & 6.7 \\
\hline ERSw & 2 & 1.0 \\
\hline ERPp & 0 & 0.0 \\
\hline ERAb & 0 & 0.0 \\
\hline NPAc & 3 & 1.4 \\
\hline NPAi & 18 & 8.7 \\
\hline $\mathrm{NPBc}$ & 48 & 23.1 \\
\hline NPSi & 0 & 0.0 \\
\hline NPIm & 2 & 1.0 \\
\hline NRIa & 3 & 1.4 \\
\hline NRIg & 32 & 15.4 \\
\hline NRSd & 4 & 1.9 \\
\hline Total & 208 & 100.0 \\
\hline
\end{tabular}

